\title{
Improved Characteristics of InGaN Multi-Quantum-Well Laser Diodes Grown on Laterally Epitaxially Overgrown GaN on Sapphire
}

Monica Hansen, Paul Fini, Lijie Zhao, Amber Abare, Larry A. Coldren, James S. Speck, and Steven P. DenBaars

Materials Department and Electrical and Computer Engineering Department, College of Engineering, University of California, Santa Barbara, California 93106

\begin{abstract}
InGaN multi-quantum-well laser diodes have been fabricated on fullycoalesced laterally epitaxially overgrown (LEO) GaN on sapphire. The laterally overgrown 'wing' regions as well as the coalescence fronts contained few or no threading dislocations. Laser diodes fabricated on the low-dislocation-density wing regions showed a reduction in threshold current density from $8 \mathrm{kA} / \mathrm{cm} 2$ to $3.7 \mathrm{kA} / \mathrm{cm} 2$ compared the those on the high-dislocation 'window' regions. Laser diodes also showed a twofold reduction in threshold current density when comparing those on the wing regions to those fabricated on conventional planar GaN on sapphire. The internal quantum efficiency also improved from $3 \%$ for laser diodes on conventional $\mathrm{GaN}$ on sapphire to $22 \%$ for laser diodes on LEO GaN on sapphire.
\end{abstract}

\section{INTRODUCTION}

InGaN-based laser diodes have potential in a number of applications such as optical storage, printing, full-color displays, chemical sensors and medical applications. Major developments in recent years have led to lifetimes in excess of 10,000 hours, demonstrating the viability of nitride laser diodes for commercial applications [1]. The implementations of lateral epitaxial overgrowth (LEO) and AlGaN/GaN modulationdoped strained-layer superlattices in the laser structure have led to increased lifetimes [2]. Strained-layer superlattices are used for strain relief to prevent cracking in the cladding layers [3], and the LEO technique has been shown to reduce the threading dislocation density in GaN grown by metalorganic chemical vapor deposition (MOCVD) [4-7] and hydride vapor phase epitaxy (HVPE) [8,9].

This reduction in dislocation density leads to benefits in device performance such as lower reverse-bias leakage current of $\mathrm{p}-\mathrm{n}$ junction diodes [10] and LEDs $[11,12]$ low gate leakage current in $\mathrm{Al}_{\mathrm{x}} \mathrm{Ga}_{1-\mathrm{x}} \mathrm{N}$ FETs [13] and low dark current, sharp cutoff $\mathrm{Al}_{\mathrm{x}} \mathrm{Ga}_{1-\mathrm{x}} \mathrm{N}$-based solar-blind photodetectors [14]. These results suggest the presence of mid-gap states associated with dislocations. For high quality coalesced LEO GaN, factors such as tilt misalignment between adjacent stripes must be carefully considered. The overgrown GaN wings have been shown to exhibit a tilt away from the seed region perpendicular to the stripe direction for both MOCVD [3,15] and HVPE [8,16] grown LEO GaN oriented in the $\langle 1 \overline{1} 00\rangle_{\mathrm{GaN}}$ or $\langle 11 \overline{2} 0\rangle_{\mathrm{GaN}}$ direction. When these tilts (typically greater than $1^{\circ}$ ) are present, a low-angle tilt boundary front with twice the magnitude of the average wing tilt is formed at the coalescence. Wing tilt has been correlated with the stripe aspect ratio in cross-section, specifically the ratio or overgrowth 
(w) to height (h). This ratio is directly dependent on growth conditions (e.g. V/III ratio, temperature) and "fill factor" (the ratio of open width to pattern period); as w/h increases, wing tilt increases $[17,18]$. Minimizing wing tilt, minimizes tilt boundary formation and its associated dislocation density at the coalescence fronts. The coalescence of the stripes must be carefully controlled to prevent dislocations from forming at the coalescence fronts to allow a larger area of reduced dislocation density for device placement.

\section{EXPERIMENTAL DETAILS}

In this study, laser diodes were fabricated on high quality fully-coalesced LEO $\mathrm{GaN}$ leading to improved device performance. Lasers fabricated on the LEO wings, along with coalescence fronts containing few or no threading dislocations, exhibit a reduced threshold current density compared to those grown on conventional planar GaN on sapphire. The internal quantum efficiency increased from $3 \%$ to $22 \%$.

InGaN multiple-quantum-well (MQW) laser diodes were grown by MOCVD in a two-flow horizontal reactor at both atmospheric and low pressure. In preparation for patterning a subsequent regrowth, a $2 \mu \mathrm{m}$ thick GaN seed layer was grown on a c-plane sapphire substrate. A $2000 \AA \mathrm{SiO}_{2}$ mask was patterned into stripes, oriented in the $\langle 1 \overline{1} 00\rangle_{\mathrm{GaN}}$ direction, defining a $5 \mu \mathrm{m}$ mask opening with a periodicity of $20 \mu \mathrm{m}$. After $\sim 6 \mu \mathrm{m}$ of LEO GaN growth on the $\mathrm{SiO}_{2}$ mask, the $\mathrm{GaN}$ stripes grew laterally and coalesced, forming a flat surface. The conditions for growth and coalescence of the LEO $\mathrm{GaN}$ are described elsewhere [18]. Next, the InGaN MQW laser structure was grown on both LEO GaN and on $2 \mu \mathrm{m} \mathrm{GaN}$ on sapphire. The structure had an active region consisting of a 3 period $\operatorname{In}_{0.13} \mathrm{Ga}_{0.87} \mathrm{~N}(40 \AA) / \mathrm{In}_{0.04} \mathrm{Ga}_{0.96} \mathrm{~N}: \mathrm{Si}(85 \AA$ ) MQW followed by a $200 \AA \mathrm{Al}_{0.2} \mathrm{Ga}_{0.8} \mathrm{~N}: \mathrm{Mg}$ cap. The $\mathrm{n}$ and $\mathrm{p}$-type cladding regions surrounding the active region consisted of $25 \AA \mathrm{Al}_{0.2} \mathrm{Ga}_{0.8} \mathrm{~N} / 25 \AA$ GaN superlattices with a total thickness of $0.45 \mu \mathrm{m}$. The cladding regions were $\mathrm{Si}$-doped for the $\mathrm{n}$-cladding and $\mathrm{Mg}$-doped for the p-cladding. A $0.1 \mu \mathrm{m} \mathrm{GaN}: \mathrm{Mg}$ layer was used as a contact layer and a $0.1 \mu \mathrm{m}$

$\mathrm{In}_{0.05} \mathrm{Ga}_{0.95} \mathrm{~N}$ :Si layer was used beneath the lower n-type cladding as a compliance layer.

Laser diodes were fabricated above the $\mathrm{SiO}_{2}$ mask in the nearly dislocation-free wing regions, above the coalescence fronts of the LEO GaN stripes, as well as above the dislocated window (seed) region. The laser cavity was oriented parallel to the direction of the $\mathrm{SiO}_{2}$ stripes. Laser facets were formed by $\mathrm{Cl}_{2}$ reactive ion etching (RIE) of $45 \mu \mathrm{m}$ wide mesas of various lengths ranging from $400 \mu \mathrm{m}$ to $1600 \mu \mathrm{m}$ and p-contact stripes were patterned on these mesas with widths ranging from $5 \mu \mathrm{m}$ to $15 \mu \mathrm{m}$. The structure was etched around the $\mathrm{p}$-contact stripe through the $\mathrm{p}$-cladding for index guiding. The $\mathrm{n}$ and p-contacts were formed by electron beam evaporation of Ti/Al and $\mathrm{Pd} / \mathrm{Au}$, respectively. Electrical testing was performed using $50 \mathrm{~ns}$ pulses with a $1 \mathrm{kHz}$ pulse repetition rate.

\section{RESULTS}

Figure 1 shows cross-section TEM micrographs of the coalescence region. There are few or no threading dislocations (with a linear density $<4 \times 10^{3} \mathrm{~cm}^{-1}$ ) generated 

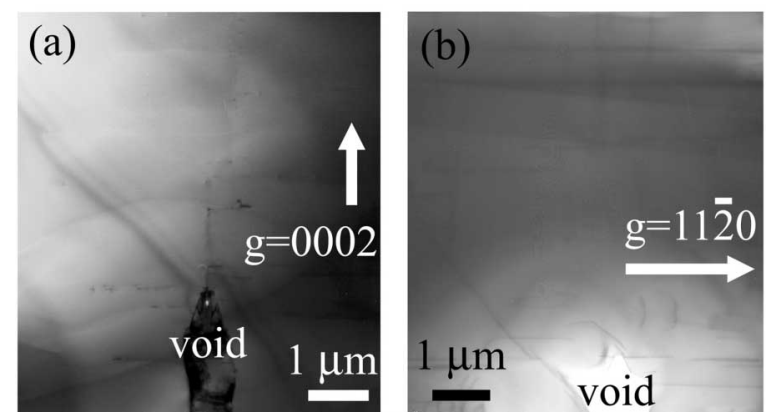

Figure 1. Bright-field cross-section TEM micrographs of a coalescence front viewed with (a) $g=0002$ and (b) $g=11 \overline{2} 0$ two-beam conditions.

at the coalescence fronts. This high quality coalescence results from low wing tilts of the laterally growing stripes. The LEO wings have a tilt of $0.1^{\circ}$ relative to the underlying seed material, which was measured using x-ray diffraction as described earlier [18].

Figure 2 shows the typical light output per uncoated facet of $5 \times 1200 \mu \mathrm{m}^{2}$ laser diodes grown on $\mathrm{LEO} \mathrm{GaN} \mathrm{as} \mathrm{a} \mathrm{function} \mathrm{of} \mathrm{forward} \mathrm{current} \mathrm{under} \mathrm{pulsed} \mathrm{operation,} \mathrm{The}$ laser diodes are placed above the wing, window and coalescence front regions. The threshold current for the laser placed on the wing, window and coalescence front regions is $340 \mathrm{~mA}, 570 \mathrm{~mA}$ and $380 \mathrm{~mA}$ respectively, resulting in respective threshold current densities of $5.7 \mathrm{kA} / \mathrm{cm}^{2}, 9.5 \mathrm{kA} / \mathrm{cm}^{2}$, and $6.3 \mathrm{kA} / \mathrm{cm}^{2}$. The corresponding threshold voltages were $15.2 \mathrm{~V}, 17 \mathrm{~V}$, and $16.1 \mathrm{~V}$ for lasers on the wing, window and coalescence fronts respectively. The minimum threshold current density was reduced by a factor of 2 from $8 \mathrm{kA} / \mathrm{cm}^{2}$ for laser diodes placed on the wing region to $3.7 \mathrm{kA} / \mathrm{cm}^{2}$ for laser diodes placed on the window region. Laser diodes grown on LEO GaN were also compared to those grown on sapphire. The minimum threshold current density was reduced by a factor of 2 from $10 \mathrm{kA} / \mathrm{cm}^{2}$ for laser diodes grown on sapphire to $4.8 \mathrm{kA} / \mathrm{cm}^{2}$ for laser

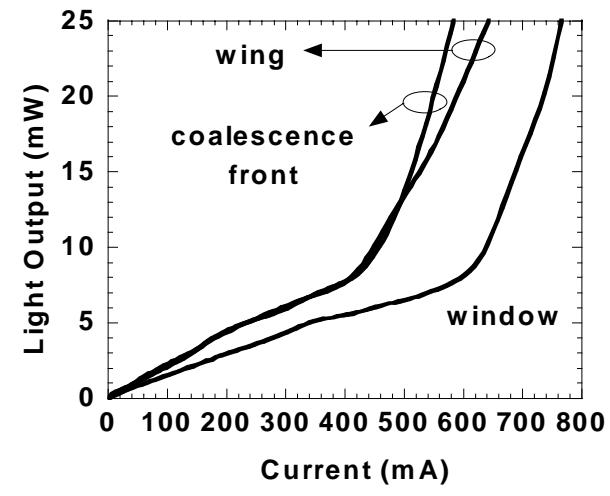

Figure 2. Typical light output per uncoated facet as a function of current for $5 \times 1200$ $\mu \mathrm{m}^{2}$ laser diodes placed on the wing, window and coalescence front on LEO GaN. 
diodes grown on LEO GaN on sapphire. The laser diodes on the LEO GaN showed this low threshold current density of $4.8 \mathrm{kA} / \mathrm{cm}^{2}$ both above the $\mathrm{SiO}_{2}$ mask regions and above the coalescence fronts of the LEO GaN. Unlike the threshold current density, the threshold voltage was not reduced as dramatically for the lasers grown on LEO GaN. The minimum threshold voltage was $21.8 \mathrm{~V}$ for lasers on LEO GaN compared to $17.4 \mathrm{~V}$ for lasers on $\mathrm{GaN} / \mathrm{sapphire}$. This reduction in threshold current density is attributed to a reduction in nonradiative recombination due to the lower dislocation density in the LEO $\mathrm{GaN}$.

Figure 3 shows the reciprocal of external differential quantum efficiency as a function of length for laser diodes grown on sapphire and LEO GaN. The external differential quantum efficiency of the laser diode increases with increasing internal quantum efficiency or decreasing internal optical loss as seen in the following relationship [19],

$$
\eta_{d}=\eta_{i} \frac{\alpha_{m}}{\left\langle\alpha_{i}\right\rangle+\alpha_{m}}
$$

where $\eta_{d}$ is the external differential quantum efficiency, $\eta_{i}$ is the internal quantum efficiency, $\alpha_{m}$ is the mirror loss and $\alpha_{i}$ is the internal optical loss of the laser. The mirror loss can be defined as

$$
\alpha_{m}=\frac{1}{L} \ln \left(\frac{1}{R}\right)
$$

where $L$ is the length and $R$ is the facet reflectivity. $R$ is estimated to be approximately 0.053 for RIE etched facets [20]. Substituting equation 2 into equation 1 and rearranging gives

$$
\frac{1}{\eta_{d}}=\frac{1}{\eta_{i}}+\frac{\left\langle\alpha_{i}\right\rangle}{\eta_{i} \ln \left(\frac{1}{R}\right)} L
$$

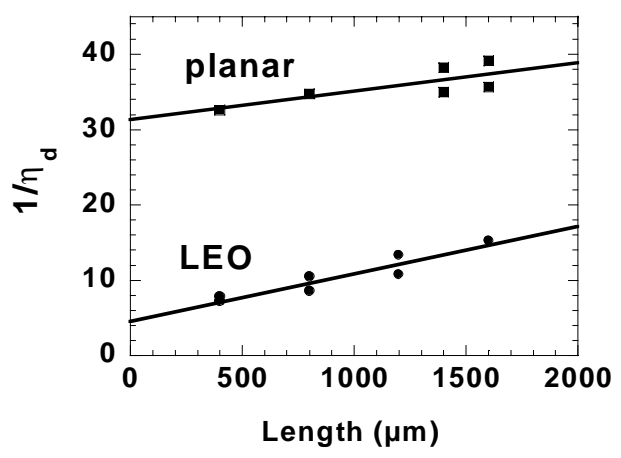

Figure 3. Inverse external differential quantum efficiency as a function of device length. 
The internal quantum efficiency can be extracted from the y-intercept of figure 3 using equation 2. The increase in external differential quantum efficiency seen in the lasers on LEO GaN compared to those on sapphire is due to a increase in the internal quantum efficiency from $\sim 3 \%$ to $\sim 22 \%$. As mentioned, the reduced reverse bias leakage current in p-n junction diodes suggests the presence of mid-gap states due to threading dislocations [21]. These mid-gap states provide nonradiative recombination centers thereby decreasing the internal quantum efficiency. Reducing the dislocation density, and hence the mid-gap states, will result in an increased internal quantum efficiency. The same effect is also seen in the spontaneous emission portion of L-I curve below threshold in figure 2 as well as in LEDs fabricated on LEO GaN [11,22], where the radiative efficiency increases with decreasing dislocation density.

\section{CONCLUSIONS}

In summary, InGaN multi-quantum well laser diodes have been fabricated on fully coalesced laterally overgrown $\mathrm{GaN}$ on sapphire. The wing regions as well as the coalescence regions of the LEO GaN contain few or no threading dislocations. The threshold current density was reduced by a factor of 2 from $10 \mathrm{kA} / \mathrm{cm}^{2}$ for laser diodes grown on sapphire substrates to $4.8 \mathrm{kA} / \mathrm{cm}^{2}$ for laser diodes grown on LEO GaN on sapphire. Laser diodes fabricated on the wing regions also showed a factor of 2 improvement as compared to those on the window regions from $8 \mathrm{kA} / \mathrm{cm}^{2}$ to $3.7 \mathrm{kA} / \mathrm{cm}^{2}$. The internal quantum efficiency also improved from $3 \%$ for laser diodes on conventional $\mathrm{GaN}$ on sapphire to $22 \%$ for laser diodes on LEO GaN on sapphire. This increase is attributed to a reduction of nonradiative recombination from a reduced dislocation density.

\section{ACKNOWLEDGEMENTS}

The authors will like to acknowledge funding support from DARPA (R. Leheny), NSF, ONR (Max Yoder, Colin Wood, Yoon-Soo Park) and Hewlett-Packard (S.Y. Wang) through the UC MICRO program.

\section{REFERENCES}

1. S. Nakamura, M. Senoh, S. Nagahama, N. Iwasa, T. Yamada, T. Matsushita, H. Kiyoku, Y. Sugimoto, T. Kozaki, H. Umemeto, M. Sano, and K. Chocho, Proc. Int. Conf. on Nitride Semicond., S-1, p. 444 (1997).

2. S. Nakamura, M. Senoh, S. Nagahama, N. Iwasa, T. Yamada, T. Matsushita, H. Kiyoku, Y. Sugimoto, T. Kozaki, H. Umemeto, M. Sano, and K. Chocho, Appl. Phys. Lett. 72, 211 (1998).

3. K. Ito, K. Hiramatsu, H. Amano, I. Akasaki, J. Cryst. Growth 104, 533 (1990).

4. D. Kapolnek, S. Keller, R. Vetury, R. D. Underwood, P. Kozodoy, S. P. DenBaars, and U.K. Mishra, Appl. Phys. Lett. 71, 1204 (1997).

5. T. S. Zheleva, O.-H. Nam, M. D. Bremser, and R. F. Davis, Appl. Phys. Lett. 71, 2472 (1997). 
6. O.-H. Nam, M. D. Bremser, T. S. Zheleva, and R. F. Davis, Appl. Phys. Lett. 71, 2638 (1997).

7. H. Marchand, J. P. Ibbetson, P. T. Fini, P. Kozodoy, S. Keller, J. S. Speck, S. P. DenBaars, and U. K. Mishra, MRS Internet J. Nitride Semicond. Res. 3, 3 (1998).

8. A. Usui, H. Sunakawa, A. Sakai, and A. A. Yamaguchi, Jpn. J. Appl. Phys. 36, L899 (1997).

9. A. Sakai, H. Sunakawa, and A. Usui, Appl. Phys. Lett. 71, 2259 (1997).

10. P. Kozodoy, J. P. Ibbetson, H. Marchand, P. T. Fini, S. Keller, S. Keller, J. S. Speck, S. P. DenBaars, and U. K. Mishra, Appl. Phys. Lett. 73, 957 (1998).

11. C. Sasaoka, H. Sunakawa, A. Kimura, M. Nido, A. Usui, and A. Sakai, J. Crystal Growth 189/190, 61 (1998).

12. S. Nakamura, M. Senoh, S. Nagahama, N. Iwasa, T. Matushita, and T. Mukai, MRS Internet J. Nitride Semicond. Res. 4S1, G1.1 (1999).

13. R. Vetury, H. Marchand, J. P. Ibbetson, P. Fini, S. Keller, J. S. Speck, S. P. DenBaars, and U.K. Mishra, Proceedings of the $25^{\text {th }}$ Int. Symp. Comp. Semicond., Nara, Japan, 1998.

14. G. Parish, S. Keller, P. Kozodoy, J. P. Ibbetson, H. Marchand, P. T. Fini, S. B. Fleischer, S. P. DenBaars, U. K. Mishra, and E. J. Tarsa, Appl. Phys. Lett. 75, 247 (1999).

15. H. Marchand, J. P. Ibbetson, P. Fini, S. Chichibu, S. J. Rosner, S. Keller, S. P. DenBaars, J. S. Speck, and U.K. Mishra, Proc. $25^{\text {th }}$ Int. Symp. Comp. Semicond., Nara Japan, 1998.

16. K. Tsukamoto, W. Taki, N. Kuwano, K. Oki, T. Shibata, N. Sawaki, and K. Hiramatsu, Proc. $2^{\text {nd }}$ Int. Symp. On Blue Laser and Light Emitting Diodes, Kisarazu, Chiba, Japan, 1998, p. 488-491.

17. P. Fini, J. P. Ibbetson, H. Marchand, L. Zhao, S. P. DenBaars, and J. S. Speck, to be published in J. Crystal Growth (1999).

18. P. Fini, L. Zhao, B. Moran, M. Hansen, H. Marchand, J. P. Ibbetson, S. P. DenBaars, U.K. Mishra, and J. S. Speck, Appl. Phys. Lett. 75, 1706 (1999).

19. L. A. Coldren and S. W. Corzine, Diode Lasers and Photonic Integrated Circuits (John Wiley \& Sons, Inc., New York, 1995), p. 53.

20. M. P. Mack, G. D. Via, A. C. Abare, M. Hansen, P. Kozodoy, S. Keller, J. S. Speck, U. K. Mishra, L. A. Coldren, and S. P. DenBaars, Electron. Lett. 34, 1315 (1998).

21. For a review on physical properties of threading dislocations in $\mathrm{GaN}$ please see J.S. Speck and S. J. Rosner, to be published in Physica B (1999).

22. M. Hansen, P. Fini, A. C. Abare, L. A. Coldren, J. S. Speck, and S. P. DenBaars, presented at the 1999 Electronic Materials Conference, Santa Barbara, CA, 1999 (unpublished). 